ISSN: $2354-1431$

http://tckh.daihoctantrao.edu.vn/

\title{
Dependence on the temperature and doped ratio of the cumulants and thermodynamic parameters in XAFS of cubic crystals
}

\author{
Nguyen Ba Duc ${ }^{a,{ }^{*}}$, Vu Quang Tho ${ }^{a}$ \\ ${ }^{a}$ Tan Trao University, Tuyen Quang, Viet Nam \\ *Email:hieutruongdhtt@gmail.com
}

\section{Article info}

\section{Recieved:}

08/7/2017

Accepted:

$03 / 8 / 2017$

\section{Tù̀ khóa:}

Phi điều hòa;

$X A F S$;

Cumulants;

Nhiệt động;

Tham số;

Tỷ lẹ.

\begin{abstract}
Thermodynamic properties and anharmonic perturbation factor of orderly doped metal crystals has described throught by terms of cumulants expansion up to the fourth-order in Xray absorption fine structure (XAFS) spectra, which have been studied base on anharmonic correlated Einsten model. Analytical expressions for dispersion relation, correlated frequency Einstein and temperature Einstein, and the XAFS cumulant up to the fourth level have been derived, the first cumulant or net thermal expansion coefficient, the second cumulant or mean square relative displacement (MSRD) or Debye-Waller factor (DWF) to describe the attenuation of x-ray scattering or coherent neutron scattering caused by thermal motion, the third cumulant and the fourth cumulant describe asymmetry for interactive potential of atoms in crystals at high temperatures, thermodynamic parameters and anharmonic perturbation factor inclusion the anharmonic effects contributions. Derived anharmonic effective potential includes contributions of all nearest neighbors of absorbing and scattering atoms to take into account three-dimensional interaction and Morse potential parameters for description single pair atomic interaction. This research aims further away, the thermodynamic parameters and cumulants not only temperature dependence but also depend on the ratio of orderly dopants crystals. Numerical results are found to be in good and reasonable agreement with those of other theories.
\end{abstract}

\section{Introduction}

To study dependence on temperature and doped ratio of alloys for the cumulants, thermal parameters and thermodynamic properties of lattice crystals of a substance, we had used X-ray Absorption Fine Structure (XAFS) spectra which it had developed into a powerful probe of atomic structure and thermal effects of substances [1-10], in which the XAFS functions provide information on atomic number of each shell, and their Fourier magnitudes provide information on radius of atomic shell [4].The thermodynamic parameters and the XAFS cumulants up to the third level have been derived for pure cubic crystals, and for doped face centered cubic (fcc) crystals are provided by correlated anharmonic Einstein model in XAFS theory [3,4,5,7]. However, the high order thermodynamic parameters, cumulants and anharmonic perturbation factor for $\mathrm{Ag}$ doped by $\mathrm{Cu}(\mathrm{AgCu})$ crystals not yet mentioned.
This works had used the anharmonic effective Einstein potential in XAFS theory [5] to formulate effective force constant, thermodynamic parameters, anharmonic perturbation factor and the four first cumulant expressions of doped $\mathrm{AgCu}$ crystals inclusion the first cumulant or net thermal expansion coefficient, the second cumulant or mean square relative displacement, the third cumulant, and the fourth cumulant describe asymmetry of atomic potential in doped crystals at high temperatures, frequency Einstein and temperature Einstein which are contained in the XAFS spectra. In this study, $\mathrm{AgCu}$ doped crystal which contain a Ag atom called absorbing atom in the XAFS process, it is nearest neighbors with host atoms and called backscattering atom $(\mathrm{Cu})$. Numerical calculation for $\mathrm{AgCu}$ doped crystal has been carried out to show the thermodynamical effects and dependence on doped ratio of fcc crystal under the influence of the doped atom. The calculated results are in good agreement with other theory $[5,10,6]$. 


\section{Formalism}

The expression of anharmonic XAFS spectra is often described by $[2,3]$ :

$$
\chi(\mathrm{k})=\frac{\mathrm{S}_{0}^{2} \mathrm{~N}}{\mathrm{kR}^{2}} \mathrm{~F}(\mathrm{k}) \exp \left(-\frac{2 \mathrm{R}}{\lambda(\mathrm{k})}\right) \operatorname{Im}\left(\mathrm{e}^{\mathrm{i} \Phi(\mathrm{k})} \exp \left(2 \mathrm{ikr} \mathrm{r}_{0}+\sum_{\mathrm{n}} \frac{(2 \mathrm{ik})^{\mathrm{n}}}{\mathrm{n} !} \sigma^{(\mathrm{n})}(\mathrm{T})\right)\right),
$$

where $\mathrm{S}_{0}^{2}$ is the intrinsic loss factor due to may electron effects and characterise for many particles effects, $\mathrm{N}$ is atomic number of a shell, $\mathrm{F}(\mathrm{k})$ is atomic backscattering amplitude, $\Phi(\mathrm{k})$ is total phase shift of photoelectron, k and $\lambda$ are wave number and mean free path of the photoelectron, respectively, and $\sigma^{(\mathrm{n})}(\mathrm{n}=1,2,3,4 \ldots)$ are the cumulants description asymmetric components, they all appear due to the thermal average of the function $\mathrm{e}^{-2 \mathrm{ikr}}$, in which the asymmetric terms are expanded in a Taylor series around value $\mathrm{R}=\langle\mathrm{r}\rangle$ with $\mathrm{r}$ is instantaneous bond length between absorbing and scattering atoms at $\mathrm{T}$ temperature.

According to the anharmonic correlated Einstein model [3, 4], effective interaction between absorbing and scattering atoms with contributions of atomic neighbors is characterized by an effective potential, to determine Debye-Waller factors described in terms of cumulants, it is necessary to specify the interatomic potential and force constant. Consider a high-order expanded anharmonic interatomic effective potential expanded up to the fourth order

$\mathrm{U}(\mathrm{x}) \approx \frac{1}{2} \mathrm{k}_{\mathrm{eff}} \mathrm{x}^{2}+\mathrm{k}_{3 \mathrm{eff}} \mathrm{x}^{3}+\mathrm{k}_{4 \mathrm{eff}} \mathrm{x}^{4}+\ldots$

with net deviation $\mathrm{x}=\mathrm{r}-\mathrm{r}_{0}$, and $\mathrm{r}$ is spontantaneous bond length between absorbing and backscattering atoms, $\mathrm{r}_{0}$ is its equilibrium value, in Eq.(2), $\mathrm{k}_{\mathrm{eff}}$ is effective spring constant because it includes total contribution of neighboring atoms, $\mathrm{k}_{3 \mathrm{eff}}$ and $\mathrm{k}_{4 \mathrm{eff}}$ are effective anharmonicity parameters which gives an asymmetry of the anharmonic effective potential.

The effective potential Eq. (2) is defined based on an assumption in the orderly center-of-mass frame of single bond pair of absorber and bacskcatterer [3,5,10]. For monatomic crystals, the masses of absorber and backscatter are the same so that it is given by:

$U_{E}(x)=U(x)+\sum_{i=1}^{2} \sum_{j \neq i} U\left(\frac{\mu}{M_{i}} \hat{\mathrm{R}}_{12} \cdot \hat{\mathrm{R}}_{\mathrm{ij}}\right)=U(x)+2 U\left(-\frac{x}{2}\right)+8 U\left(-\frac{x}{4}\right)+8 U\left(\frac{x}{4}\right)^{(3)}$

where the first term on the right concerns only absorber and backscatter atoms, the sums extend over their nearest neighbors, and the second equality is for fec structure of
Ag orderly doped $\mathrm{Cu}$. Hence, this effective pair potential describes not only pair interaction of absorber and backscatter atoms themselves, but also an affect of their near neighbors atoms on such interaction. It is the difference of our effective potential from the single-pair potential [10] and single-bond potential [1,3] which concern only each pair of immediate neighboring atoms, e.g., only $\mathrm{U}(x)$, without the remaining terms on the right of Eq. (3). In Eq.(3), $\hat{\mathrm{R}}$ is the unit bond length vector, $\mu$ is reduced mass of atomic mass $M_{1}$ (of $\mathrm{Ag}$ ) and $\mathrm{M}_{2}$ (of $\mathrm{Cu}$ ), the sum according to $\mathrm{i}, \mathrm{j}$ is the contribution of cluster nearest atoms. The atomic vibration is calculated based on quantum statistical procedure with approximate quasi - harmonic vibration, in which the Hamiltonian of the system is written as harmonic term with respect to the equilibrium at a given temperature plus an anharmonic perturbation.

$\mathrm{H}=\frac{\mathrm{P}^{2}}{2 \mu}+\mathrm{U}_{\mathrm{E}}(\chi)=\mathrm{H}_{0}+\mathrm{U}_{\mathrm{E}}(\mathrm{a})+\delta \mathrm{U}_{\mathrm{E}}(\mathrm{y}) ; \quad \mathrm{H}_{0}=\frac{\mathrm{P}^{2}}{2 \mu}+\frac{1}{2} \mathrm{k}_{\text {eff }} \mathrm{y}^{2}$

with $\mathrm{y}=\mathrm{x}-\mathrm{a}, \mathrm{a}(\mathrm{T})=\langle\mathrm{x}\rangle,\langle\mathrm{y}\rangle=0$, where $\mathrm{a}$ is the net thermal expansion, $y$ is the deviation from the equilibrium value of $\mathrm{X}$ at temperature $\mathrm{T}$. Use of potential interaction between each pair of atoms in the single bond can be expressed by anharmonic Morse potential for cubic crystals and expanding to four order around its minimum, we have:

$\mathrm{U}_{\mathrm{E}}(\mathrm{x})=\mathrm{D}\left(\mathrm{e}^{-2 \alpha \mathrm{x}}-2 \mathrm{e}^{-\alpha \mathrm{x}}\right) \approx \mathrm{D}\left(-1+\alpha^{2} \mathrm{x}^{2}-\alpha^{3} \mathrm{x}^{3}+\frac{7}{12} \alpha^{4} \mathrm{x}^{4} \ldots\right)$

where $\mathrm{D}$ is the dissociation energy by $\mathrm{U}\left(\mathrm{r}_{0}\right)=-\mathrm{D}$, and $\alpha$ describes the width of the potential. In the case assumption of orderly dopant crystals, we have expression of the Morse potential formed:

$\mathrm{U}_{\mathrm{E}}(\mathrm{x})=\mathrm{D}_{12}\left(-1+\alpha_{12}^{2} \mathrm{x}^{2}-\alpha_{12}^{3} \mathrm{x}^{3}+\frac{7}{12} \alpha_{12}^{4} \mathrm{x}^{4} \ldots\right)$

Morse potential parameters in Eq.(6) have been obtained by expressions as follow:

$\alpha_{12}^{2} \cong \frac{D_{1} \alpha_{1}^{2}+D_{2} \alpha_{2}^{2}}{D_{1}+D_{2}}, \quad \alpha_{12}^{3} \cong \frac{D_{1} \alpha_{1}^{3}+D_{2} \alpha_{2}^{3}}{D_{1}+D_{2}}, \quad D_{12} \cong \frac{D_{1}+D_{2}}{2}$

From expressions (3), (6) we have effective interaction Einstein potential as:

$U_{E}(x)=U_{E}(a)+\frac{1}{2} k_{e f f} y^{2}+\delta U_{E}(y)$,

Substituting Eq. (6) with $\mathrm{x}=\mathrm{y}+\mathrm{a}$ into (3) and using Eq. (8) to calculate the second term in Eq. (2) with reduced mass of pure metals and metals doped: 
$\mu_{1} \approx \frac{\mathrm{M}_{1}}{2}=\frac{\mathrm{m}_{01}}{2} \times \mathrm{m}_{\mathrm{p}} ; \quad \mu_{2} \approx \frac{\mathrm{M}_{2}}{2}=\frac{\mathrm{m}_{02}}{2} \times \mathrm{m}_{\mathrm{p}} ; \quad \mu_{12} \approx \frac{2 \mu_{1} \mu_{2}}{\mu_{1}+\mu_{2}}$

with $\mathrm{m}_{0}$ is atomic mass number, $\mathrm{m}_{\mathrm{p}}=938.27231 \mathrm{MeV} / \mathrm{c}^{2}$ is mass of a proton in atoms. To calculation of $\left(\hat{\mathrm{R}}_{12} \cdot \hat{\mathrm{R}}_{\mathrm{ij}}\right)$ with lattice fcc crystals, applying Morse potential in Eq. (6) to Eq. (5) and comparing the results to Eq. (4), we determine the $\mathrm{k}_{\text {eff }}, \mathrm{k}_{3 \mathrm{eff}}, \mathrm{k}_{4 \mathrm{eff}}$ coefficients of the anharmonic effective potential in terms of Morse potential parameters.

$\mathrm{k}_{\mathrm{eff}}=5 \mathrm{D}_{12} \alpha_{12}^{2} ; k_{3 e f f}=\frac{5 D_{12} \alpha_{12}^{3}}{4} ; \mathrm{k}_{4 \mathrm{eff}}=\frac{17 \mathrm{D}_{12} \alpha_{12}^{4}}{35} ;$

To derive the analytical formulas of cumulants of the fcc crystals, we use perturbation theory [1,5]. The atomic vibration is quantized as phonon, with consideration of the phonon-phonon interaction for taking into account the anharmonicity, in the classical limit and assumption with we obtain the cumulants up to third level:

$\sigma^{(1)}=\langle\mathrm{x}\rangle=\frac{3 \hbar \omega_{\mathrm{E}}}{40 \mathrm{D}_{12} \alpha_{12}} \frac{(1+\mathrm{z})}{(1-\mathrm{z})}$

$\sigma^{(2)}=\left\langle x^{2}\right\rangle-\langle x\rangle^{2} \approx\left\langle x^{2}\right\rangle=\frac{\hbar \omega_{E}}{10 D_{12} \alpha_{12}^{2}} \frac{(1+z)}{(1-z)}$

$\sigma^{(3)}=\left\langle x^{3}\right\rangle-3\left\langle x^{2}\right\rangle\langle x\rangle+2\langle x\rangle^{2}=\frac{3 \hbar^{2} \omega_{\mathrm{E}}^{2}}{200 D_{12}^{2} \alpha_{12}^{3}} \frac{\left(1+10 z+z^{2}\right)}{(1-z)^{2}} ;$

and the fourth-order cumulant have been decided by:

$\sigma^{(4)}=\left\langle x^{4}\right\rangle-4\left\langle x^{3}\right\rangle\langle x\rangle-3\left\langle x^{2}\right\rangle^{2}-12\left\langle x^{2}\right\rangle\langle x\rangle^{2}-6\langle x\rangle^{4} \approx\left\langle x^{4}\right\rangle-3\left\langle x^{2}\right\rangle^{2} ;$

The calculation $\left\langle x^{4}\right\rangle$ is analogous to the one $\langle x\rangle$ in Eq.(11), and using $\left\langle x^{2}\right\rangle$ from Eq.(12) we obtain $3\left\langle x^{2}\right\rangle^{2}$. Substituting these values in to $\sigma^{(4)}$ and using the phonon momentum conservation in the first Brillouin zone, the fourth cumulant in terms of Morse parameters has results as:

$\sigma^{(4)}=\frac{137 \hbar^{3} \omega_{\mathrm{E}}^{3} 10^{-4}}{4 \mathrm{D}_{12}^{3} \alpha_{12}^{4}} \frac{(1+\mathrm{z})^{3}}{(1-\mathrm{z})^{3}} ;$

in Eqs.(11-14), $\mathrm{Z} \equiv \mathrm{e}^{-\beta \hbar \omega_{\mathrm{E}}}=\mathrm{e}^{-\theta_{\mathrm{E} /} / \mathrm{T}}$ is the temperature variable and determined by the Einstein temperature $\theta_{\mathrm{E}}=\frac{\hbar \omega_{\mathrm{E}}}{\mathrm{k}_{\mathrm{B}}}$, with $\mathrm{k}_{\mathrm{B}}$ is Boltzmann's constant. The total MSRD (Mean Square Relative Displacement) is described as the sum of the harmonic term $\sigma^{2}$ and the anharmonic contribution $\sigma_{\mathrm{A}}^{2}[3,4]$ which in the present theory, we have: $\sigma_{\text {tot }}^{2}(T)=\sigma^{2}(T)+\sigma_{A}^{2}(T) ; \quad \sigma_{A}^{2}(T)=\beta(T) \sigma^{2}(T)$

where $\sigma^{2}$ is calculated using Eq. (12) and the anharmonic factor $\beta$ is given by:

$\beta(T)=\frac{15}{7} \alpha_{12}^{2} \sigma^{2}\left[1+\frac{4}{5 R} \alpha_{12} \sigma^{2}\left(1+\frac{2}{3 R} \alpha_{12} \sigma^{2}\right)\right]$

which is defined based on the second cumulant $\sigma^{2}$ and $\mathrm{R}$ is the first shell radius. Anharmonic perturbation factor $\partial \mathrm{U}_{\mathrm{E}}(\mathrm{y})$ has determined form:

$\delta \mathrm{U}_{\mathrm{E}}(\mathrm{y})=5 \mathrm{D}_{12} \alpha_{12}^{2}\left(\mathrm{a}(\mathrm{a}-\mathrm{x})-\frac{\alpha_{12}(\mathrm{a}-\mathrm{x})^{3}}{4}\right)$

Anharmonic perturbation factor $\partial \mathrm{U}_{\mathrm{E}}(\mathrm{y})$ dependence $T$ temperature and net deviation $x$.

\section{Comparison}

We applied the expressions which is derived in the previous section to numerical calculation for orderly mixed crystal is $\mathrm{AgCu}$. According to Morse potential parameters for pure $\mathrm{Ag}, \mathrm{Cu}$ crystals have been known $[3,4,8]$, we calculated parameters $D_{12}$ and $\alpha_{12}$ to shown on Table 1 .

Table 1. Morse potential parameters values for crystals

\begin{tabular}{ccc}
\hline Crystals & $\mathrm{D}_{12}(\mathrm{eV})$ & $\alpha_{12}\left(\AA^{-1}\right)$ \\
\hline $\mathrm{Ag}-\mathrm{Ag}$ & 0.3323 & 1.3690 \\
$\mathrm{Cu}-\mathrm{Cu}$ & 0.3429 & 1.3588 \\
$\mathrm{Ag}-\mathrm{Cu}$ & 0.3376 & 1.3638 \\
\hline
\end{tabular}

Substituting $\mathrm{D}_{12}, \alpha_{12}$ thermodynamic parameters from Table 1 into Eqs. $(9,10)$ with Boltzmann's constant $k_{B}=8.617 \times 10^{-5} \mathrm{eV} \AA^{-1}$, Plank's constant $\hbar=6.5822 \times 10^{-16} \mathrm{eV} . \mathrm{s}$, we calculated values of the $\mathrm{k}_{\text {eff, }} \mathrm{k}_{3 \mathrm{eff}}, \mathrm{k}_{4 \text { eff }}$ coefficients of the anharmonic effective potential in terms of Morse potential parameters according to Table 2 .

Table 2. Anharmonic effective parameters values

\begin{tabular}{cccc}
\hline Crystals & $\mathrm{k}_{\text {eff }}(\mathrm{N} / \mathrm{m})$ & $\mathrm{k}_{3 \text { eff }}$ & $\mathrm{k}_{4 \text { eff }}$ \\
\hline $\mathrm{Ag}-\mathrm{Ag}$ & 3.114 & 1.0657 & 0.5669 \\
$\mathrm{Cu}-\mathrm{Cu}$ & 5.0648 & 1.0458 & 0.5535 \\
$\mathrm{AgCu}$ & 3.1397 & 1.0705 & 0.5673 \\
\hline
\end{tabular}

Other thermodynamic parameters as reduced mass $\mu_{12}$, correlated Einstein frequency $\omega_{E}$ and Einstein temperature $\theta_{\mathrm{E}}$ according to Table 3 .

Table 3. Thermodynamic parameters values $\mu, \omega_{\mathrm{E}}, \theta_{\mathrm{E}}$

\begin{tabular}{cccc}
\hline Crystals & $\mu\left(\mathrm{eV} / \AA^{2} . \mathrm{s}^{-2}\right)$ & $\omega_{\mathrm{E}}\left(10^{13} \mathrm{~Hz}\right)$ & $\theta_{\mathrm{E}}(\mathrm{K})$ \\
\hline $\mathrm{Ag}-\mathrm{Ag}$ & $0.5623 .10^{-26}$ & 3.3933 & 176 \\
$\mathrm{Cu}-\mathrm{Cu}$ & $0.3310 .10^{-26}$ & 3.0927 & 236 \\
$\mathrm{AgCu}$ & $0.4166 .10^{-26}$ & 2.7453 & 209 \\
\hline
\end{tabular}


Substituting values of thermodynamic parameters from Tabs. (2, 3) into Eqs. (11-17), we received the expressions of cumulants, anharmonic factor and anharmonic perturbation factor to describe the dependence on temperature and doped ratio of orderly compounds of cumulants and thermal expansion coefficient, anharmonic perturbation factor.

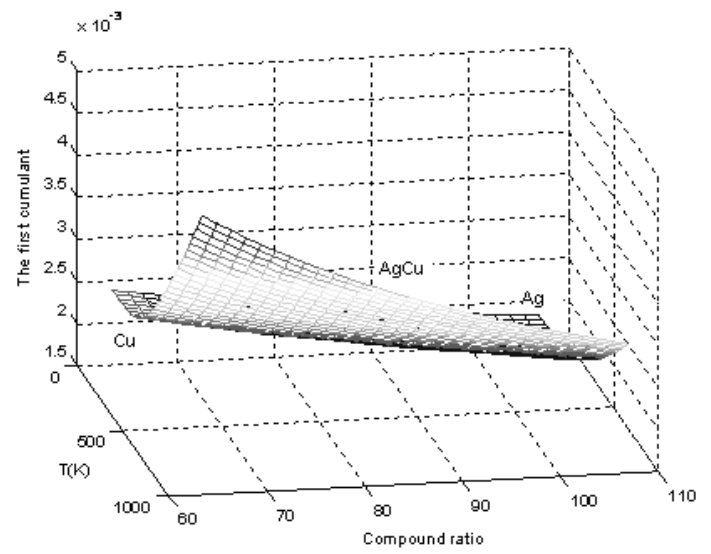

Figure 1: Dependence on the temperature and compound ratio of the first cumulant $\sigma^{(1)}(\mathrm{T})$

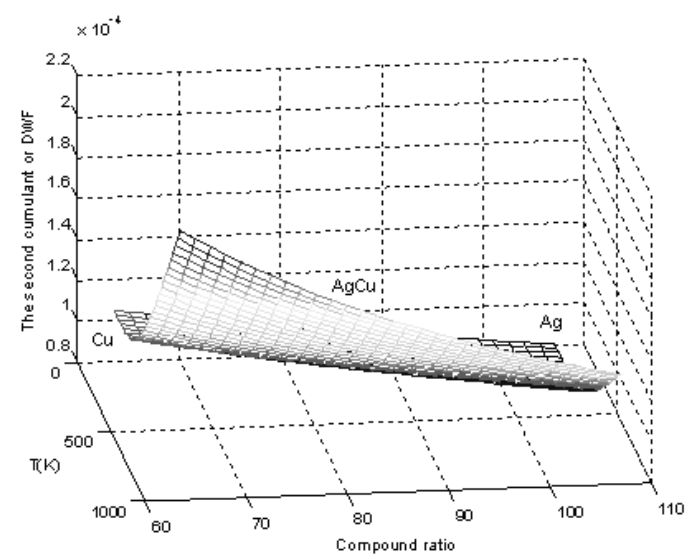

Figure 2: Dependence on the temperature and compound

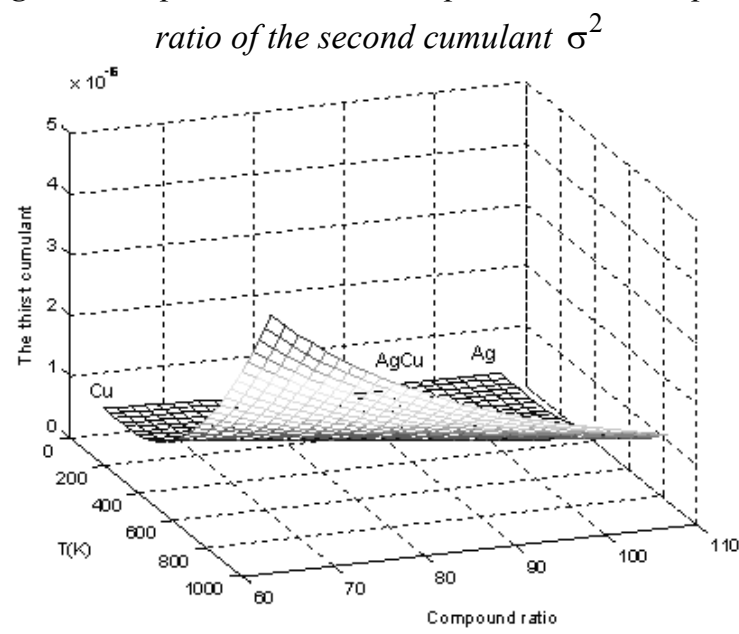

Figure 3: Dependence on the temperature and compound ratio of the third cumulant $\sigma^{(3)}(\mathrm{T})$
Figure 1 illustrates the dependence on temperature and doped ratio of the first cumulant $\sigma^{(1)}(\mathrm{T})$ or net thermal expansion and Figure 2 illustrates the dependence on temperature and doped ratio of our calculated anharmonic contribution the second cumulant $\sigma^{(2)}(\mathrm{T})$ or the mean square relative displacement (MSRD) of $\mathrm{AgCu}$ orderly mixed crystal. Figure 3 illustrates the dependence on temperature and doped ratio of the third cumulant $\sigma^{(3)}(\mathrm{T})$ of $\mathrm{AgCu}$ crystal. According to this theoretical results, the form of graphs of $\sigma^{(1)}(\mathrm{T}), \sigma^{(2)}(\mathrm{T}), \sigma^{(3)}(\mathrm{T})$ have the style similar to that of the line that depicts the dependence on temperature of the pure crystals of cumulants in other theories $[5,6,10]$ and varies with the rate of conversion from copper $(\mathrm{Cu})$ to silver $(\mathrm{Ag})$ crystals. For $\sigma^{(1)}(\mathrm{T})$ (Figure 1 ), at $0 \mathrm{~K}$ we have $\sigma_{0}^{(1)}(C u)=0,0024 A^{0} ; \quad \sigma_{0}^{(1)}(A g C u)=0,0021 A^{0} \quad$ with $50 \%$ atomic number ratio of $\mathrm{Ag}-\mathrm{Cu}$ and $\sigma_{0}^{(1)}(A g)=0,0018 A^{0}$, ie the first cumulant or net thermal expansion coefficient values are reduced evenly, that mean, at $0 \mathrm{~K}$ temperature pure silver crystals are more stable than silver crystal doped with copper and are more stable than pure copper crystal, at $500 \mathrm{~K}$ temperature $\sigma^{(1)}(C u)=0,0029 A^{0}$, $\sigma^{(1)}(A g C u)=0,0025 A^{0}$ and $\sigma^{(1)}(A g)=0,0020 A^{0}$, that mean $\sigma^{(1)}(\mathrm{AgCu})$ with $50 \%$ atomic number ratio $\mathrm{Ag}-\mathrm{Cu}$ crystals is reduced $13,79 \%$ comparison with $\sigma^{(1)}(C u)$ the pure cupper crystal, and $\sigma^{(1)}(A g)$ is reduced $20 \%$ comparison with $\sigma^{(1)}(\mathrm{AgCu})$, at $1000 \mathrm{~K}$ temperature $\sigma^{(1)}(C u)=0,0048 A^{0}, \quad \sigma^{(1)}(A g C u)=0,0037 A^{0} \quad$ and $\sigma^{(1)}(A g)=0,0030 A^{0}$, that mean $\sigma^{(1)}(A g C u)$ with $50 \%$ atomic number ratio $\mathrm{Ag}-\mathrm{Cu}$ crystals is reduced 22,9\% comparison with $\sigma^{(1)}(\mathrm{Cu})$ the pure cupper crystal, and $\sigma^{(1)}(A g) \quad$ is reduced $18,92 \%$ comparison with $\sigma^{(1)}(A g C u)$. We notice, alloys with larger copper ratios will be less durable than silver alloys with higher silver ratio. When temperatures from $500 \mathrm{~K}$ to $700 \mathrm{~K}$, the first cumulant of $\mathrm{AgCu}$ (50-50 compound ratio) decreases slowly but when the temperature reaches $1000 \mathrm{~K}$, the first cumulant decreases faster, so that alloys with greater silver ratio will be more durable at $500 \mathrm{~K}-700 \mathrm{~K}$. 


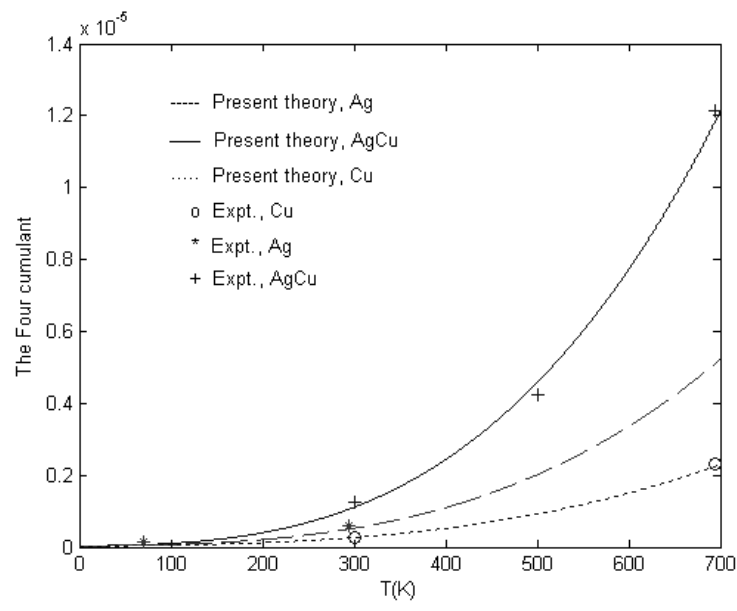

Figure 4: Temperature dependence of four cumulant $\sigma^{(4)}(\mathrm{T})$

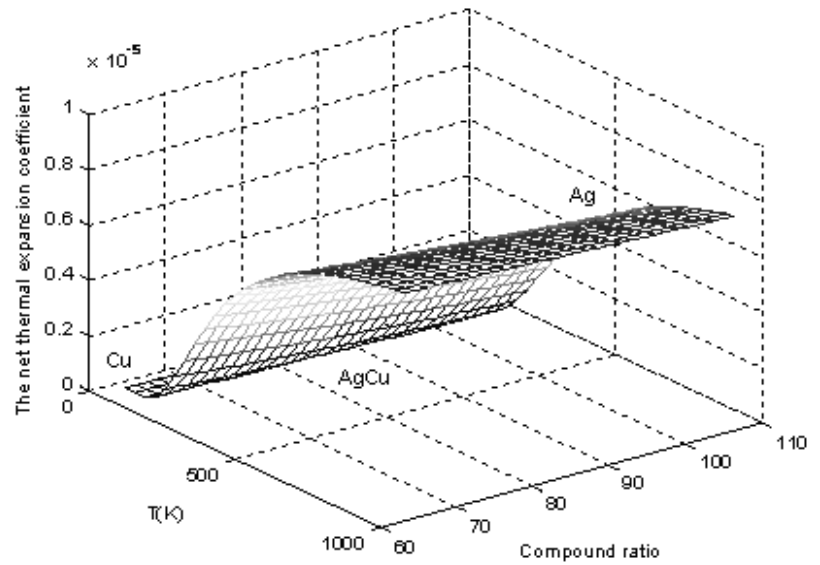

Figure 5: Dependence on the temperature and compound ratio of thermal expansion constant $\alpha_{\mathrm{T}}$

For the second cumulant or Debye-Waller factor $\sigma^{(2)}(\mathrm{T})$ (Figure 2) to describe the attenuation of x-ray scattering or coherent neutron scattering caused by thermal motion. At $0 \mathrm{~K}$ we have $\sigma_{0}^{2}(C u)=0,1049 \times 10^{-3}\left(A^{0}\right)^{2} ; \sigma_{0}^{2}(A g C u)=0,0910 \times 10^{-3}\left(A^{0}\right)^{2}$ with $50 \%$ atomic number ratio of $\mathrm{Ag}-\mathrm{Cu}$ and $\sigma_{0}^{2}(A g)=0,0809 \times 10^{-3}\left(A^{0}\right)^{2}$, and at $500 \mathrm{~K}$ we have $\sigma_{0}^{2}(C u)=0,1292 \times 10^{-3}\left(A^{0}\right)^{2}$; $\sigma_{0}^{2}(\mathrm{AgCu})=0,1054 \times 10^{-3}\left(A^{0}\right)^{2}, \quad$ and $\sigma_{0}^{2}(A g)=0,0899 \times 10^{-3}\left(A^{0}\right)^{2}$ and at $1000 \mathrm{~K}$ we have $\sigma_{0}^{2}(C u)=0,2106 \times 10^{-3}\left(A^{0}\right)^{2} ;$

$\sigma_{0}^{2}(A g C u \quad)=0,1628 \times 10^{-3}\left(A^{0}\right)^{2}$ and $\sigma_{0}^{2}(A g)=0,1324 \times 10^{-3}\left(A^{0}\right)^{2}$. So that at $0 \mathrm{~K}$, when $\mathrm{Ag}$ crystal ratio increase comparison with $\mathrm{Cu}$ crystal in compound, the attenuation of x-ray scattering (the second cumulant or Debye-Waller factor) is decreased 13,25\% and only decrease $11,1 \%$ from $\mathrm{AgCu}$ ratio $50 \%$ to pure $\mathrm{Ag}$ crystal, at $500 \mathrm{~K}$ the attenuation of $\mathrm{x}$-ray scattering is strongly reduced to $18,42 \%$ and less decrease with
14,71\% from $\mathrm{AgCu}$ atomic number ratio $50 \%$ to pure $\mathrm{Ag}$ crystal, and very strong decrease $22,7 \%$ and $18,67 \%$, respectively, at $1000 \mathrm{~K}$ temperature. Meaning that the scattering attenuation of $\mathrm{x}$-ray is smaller.

For the third cumulant $\sigma^{(3)}(\mathrm{T})$ (Figure 3) and fourth cumulant $\sigma^{(4)}(T)$ (Figures 4) shows contribution in to phrase shift of XAFS spectra very strong at hight temperature comparing to the low temperature, that mean calculation expressions in this work agreement with other theories. At the same time, when ratio of $\mathrm{Cu}$ crystal is greater than of Ag crystal in compound, which makes the phase shift dramatically strongly change (Figure 3 ).

The temperature dependence of the four cumulant $\sigma^{(4)}(\mathrm{T})$ (Figure 4) calculated using Eq.(14) for $\mathrm{Ag}, \mathrm{Cu}$ and $\mathrm{AgCu}$ agrees well with experiment not only $500 \mathrm{~K}$ and $700 \mathrm{~K}$ but also at $77 \mathrm{~K}[3,7]$. Hence, the present classical theory can be applied to the third and four cumulants of fcc crystals from the temperatures which are much lower than their Einstein temperature. The reason of the above conclusions is attributed to the absent of zero-point vibrations, wich are non-negligible for the cumulants $\sigma^{(1)}, \sigma^{2}$, and negligibly small for $\sigma^{(3)}$ and $\sigma^{(4)}$ cumulants, this is quantum effects. At high temperatures, the cumulants $\sigma^{(1)}, \sigma^{2}$ are linear proportional to the $T$ temperature, and the third cumulant $\sigma^{(3)}, \sigma^{(4)}$ is proportional to the square temperature $\mathrm{T}^{2}, \mathrm{~T}^{3}$, respectively. Figure 5 illustrates the dependence on temperature and atomic number ratio of net thermal expansion constant $\alpha_{\mathrm{T}}$ of $\mathrm{Ag}, \mathrm{Cu}$ and $\mathrm{AgCu}$ in our calculated, they have the form of specific heat, thus reflecting the fundamental of solid state theory, that the thermal expansion is the result of anharmonic effects and is also proportional to specific heat, and $\alpha_{\mathrm{T}}$ factor approach constant values at high temperatures and it is approximate zero at low temperature, thus agree with classical theory and other theories $[5,6,10]$.

\section{Conclusion}

A new analytical theory for calculation and evaluation of the thermodynamic properties of $\mathrm{AgCu}$ crystals has been developed based on the quantum statistical theory with the effective anharmonic Einstein potential developed for the orderly doping fcc crystals. The expressions for the thermodynamic parameters, effective force constant, correlated Einstein frequency and temperature, the cumulant expansion up to the fourth order, thermal expansion coefficient, anharmonic 
perturbation factor and anharmonic factor in anharmonic XAFS spectra of $\mathrm{AgCu}$ crystals including orderly doped crystals agree with all standard properties of these quantities. The quantitive calculation for the orderly doping crystals has the same form as for the pure crystals themselves.

The well agreement between the results of calculated theory and the other theories demonstrates possibility that is may be used the present developed theory in XAFS data analysis.

\section{Acknowledgement}

The authors thanks Prof. Nguyen Van Hung (Ha Noi University of Science) for useful discussions and for authorizing the author to use some results published, thanks Prof. Cao Long Van (Institute of Physics University of Zielona Gora, Poland) for useful comments. Thanks the Project No. DT.11 - 2016 of Tuyen Quang province has suppoted financial during study.

\section{REFERENCES}

1. A. I. Frenkel and J. J. Rehr, Phys. Rev. B 48 (1993) 585. 11 ;

2. E. D. Crozier, J. J. Rehr, and R. Ingalls, in X-ray
Absorption, edited by D. C. Koningsberger and R. Prins (Wiley, New York, 1988);

3. Hung N.V., Duc N. B., Frahm R.R., (2002), J.Phys.Soc., Japan, Vol. 72, No. 5, pp 1254-1259;

4. Hung N. V., Ronald Frahm and Hiromichi Kamitsubo, (1996), J.Phys.Soc., Japan, Vol.65, No 11, pp 35713575 ;

5. Hung, N. V. and Rehr, J. J., (1997), Phys. Rev. B (56), pp. 43 ;

6. Hung N V, Toan N. C., Duc N. B., and Vuong D. Q., (2015) OpenPhys., 13: 242-246;

7. N. V. Hung and N. B. Duc, J. Communications in Physics, vol. 10, Nº. 1, pp. 15-21 (2000);

8. Nguyen Ba Duc, (2015), American Association for Science and Technology (AASCIT-Journal of Physics), Vol.1, pp1-5;

9. Nguyen Van Hung, Nguyen Bao Trung, Nguyen Ba Duc, (2015), Journal of Materials Sciences and Applications, 1(3): 91-97;

10. T. Miyanaga and T. Fujikawa, J. Phys. Soc. Jpn. 63 (1994) 1036 and 3683.

\section{Thông tin bài viết}

Ngày nhận bài:

08/7/2017

Accepted:

03/8/2017

\section{Tù khóa:}

Phi điều hòa,

$X A F S$;

Cumulants

Nhiệt động,

Tham số;

Tỷ lệ;

\section{Tóm tắt}

Các tính chất nhiệt động và hệ số nhiễu loạn phi điều hòa của các tinh thể pha tạp có trật tự đã được mô tả qua việc khai triển các cumulant tới bậc 4 trong phổ cấu trúc tinh tế của hấp thụ tia $X$ (XAFS), qua nghiên cứu dựa trên cơ sở mô hình Einstein tương quan phi điều hòa. Các biểu thức giải tích về sự tán sắc tương quan, tần số và nhiệt độ tương quan Einstein, cumulant bậc 4 của phổ cấu trúc tinh tế hấp thụ tia $\mathrm{X}$ đã được xác định. Cumulant bậc 1 hay hệ số giãn nở nhiệt mạng, cumulant bậc 2 hay độ dịch chuyển tương đối trung bình toàn phương (MSRD) hay hệ số DebyeWaller (DWF) đã mô tả sự suy giảm của tán xạ tia $\mathrm{X}$ hay tán xạ notron kết hợp gây ra do chuyển động nhiệt. Cumulant bậc 3 và cumulant bậc 4 mô tả sự bất đối xứng của thế tương tác của các nguyên tử ở nhiệt độ cao, các tham số nhiệt động và hệ số nhiễu loạn phi điều hòa bao gồm các đóng góp của ảnh hưởng phi điều hòa. Đã xác định được thế hiệu dụng phi điều hòa bao gồm các đóng góp của các nguyên tử hấp thụ và tán xạ gần nhất được tính toán theo tương tác ba chiều và các tham số thế Morse mô tả tương tác nguyên tử đơn cặp. Mục tiêu xa hơn của nghiên cứu này là các tham số nhiệt động và các cumulant không chỉ phụ thuộc vào nhiệt độ mà còn phụ thuộc vào tỷ lệ của các tinh thể pha tạp có trật tự. Các kết quả tính toán số phù hợp với những kết quả của các phương pháp lý thuyết khác. 